\title{
Long-term outcomes of laparoscopy vs. open surgery for colorectal cancer in elderly patients: A meta-analysis
}

\author{
WANG FUGANG $^{1,2}$, YU ZHAOPENG ${ }^{1,2}$, ZHAO MENG $^{2}$ and SONG MAOMIN $^{2}$ \\ ${ }^{1}$ The Fifth Clinical Medical College, Capital Medical University, Beijing 100069; ${ }^{2}$ Department of General Surgery, \\ Beijing Tiantan Hospital, Beijing 100050, P.R. China
}

Received May 31, 2017; Accepted August 25, 2017

DOI: $10.3892 / \mathrm{mco} .2017 .1419$

\begin{abstract}
The long-term outcome of laparoscopic surgery for geriatric patients with colorectal cancer remains unclear due to decreased functional reserves and increased medical comorbidities. A meta-analysis was performed in the present study to compare the long-term outcome between laparoscopy and laparotomy. Randomized controlled trials and comparative studies regarding laparoscopy vs. open surgery for colorectal cancer in elderly patients were searched in Pubmed, Embase, and Cochrane library between inception and April 20,2017. The methodological quality of the cohort studies was evaluated using the Newcastle-Ottawa Scale. The meta-analysis was performed using Stata v12.0 software. Eight cohort studies were enrolled in the meta-analysis. Laparoscopic surgery was associated with a higher 3-year survival rate compared with open surgery [risk ratio (RR), 0.74; 95\% confidence interval (CI), 0.61-0.90; $\mathrm{P}=0.003]$. No significant difference was identified between laparoscopy and laparotomy regarding the 5-year survival rate (RR, 0.93; 95\% CI, 0.78-1.11, $\mathrm{P}=0.424)$. The results of the meta-analysis indicated that the use of laparoscopic surgery on geriatric patients with colorectal cancer should be increased due to more improved long-term outcomes. All the studies included in the meta-analysis were case-control studies with selection bias and other confounding factors. Thus, larger sample sizes and multicenter randomized controlled trials are required to further validate the use of laparoscopic surgery as the preferred therapeutic option for elderly patients with colorectal cancer.
\end{abstract}

Correspondence to: Professor Song Maomin, Department of General Surgery, Beijing Tiantan Hospital, No. 6 Tiantanxili Road, Beijing 100050, P.R. China

E-mail: songmaomin@163.com

Abbreviations: CI, confidence interval; RR, risk ratio; $\mathrm{R}$, rectal cancer; C, colon cancer; CRC, colorectal cancer; CS, cohort study; lap, laparoscopy; Open, open surgery; NM, not mentioned

Key words: colorectal neoplasms, laparoscopic, open surgery, elderly

\section{Introduction}

Colorectal cancer is a common malignancy worldwide with approximately 1400,000 newly diagnosed cases and 694,000 cancer-related death cases (1). Due to the increasing life expectancy, earlier diagnosis and improved surgery, pre- and postoperative oncological treatment and regular checkups, the proportion of elderly colorectal cancer patients has been on the increase (2), reaching up to $75 \%$ as reported by Hermans et al (3). Elderly patients of colorectal cancer frequently experience decreased functional reserve and increased comorbidities such as cardiovascular and pulmonary diseases, which make them under-represented in clinical trials (2). In general colorectal cancer patients, laparoscopy can achieve shorter hospital stay, faster postoperative recovery, equal local recurrence rate, as well as disease-free and overall survival $(4,5)$.

In elderly colorectal cancer patients, comparative clinical trials concerning laparoscopic vs. open surgery are limited. Several meta-analyses compared the short-term outcomes between laparoscopy and laparotomy for elderly colorectal cancer patients and concluded that laparoscopic surgery achieved less intraoperative blood loss (6), longer operating time (6), shorter length of hospital stay (6-8), lower postoperative morbidity and rapid bowel function recovery (6-8). To the best of our knowledge, no meta-analysis of laparoscopy vs. laparotomy has been performed with regard to long-term outcomes for elderly colorectal cancer patients.

In the present meta-analysis, we collected data from previous studies to perform a meta-analysis of laparoscopy vs. laparotomy concerning long-term outcomes for elderly colorectal cancer patients with the aim of selecting improved surgical techniques in this age subgroup.

\section{Data collection methods}

Search strategy. Studies were searched with regard to the comparison of long-term outcomes between laparoscopy and open surgery for elderly colorectal cancer patients from inception to April 20, 2017. The search strategy for Medline and other databases involved the following key words: (((('Colorectal Neoplasms' [MeSH] OR 'Rectal Neoplasms'[MeSH] OR 'Colonic Neoplasms'[MeSH] OR colectomy[Title] OR sigmoidectomy[Title] OR 'Colorectal 
resection'[Title))] AND (laparoscopically[Title/Abstract] OR laparoscopic[Title/Abstract] OR laparoscopy[Title/Abstract))] AND (open[Title/Abstract] OR laparotomy[Title/Abstract))] AND (elder[Title/Abstract] OR elderly[Title/Abstract] OR old[Title/Abstract] OR aged[Title/Abstract] OR octogenarian[Title/Abstract]OR nonagenarian[Title/Abstract] ORoctogenarians[Title/Abstract]ORnonagenarians[Title/Abstract] OR older[Title/Abstract)]. Randomized control trials (RCTs), two-arm prospective studies, retrospective studies, and cohort studies were included. The reference list of potential studies was searched manually for eligibility by two independent reviewers, and if there was disagreement regarding inclusion, a third reviewer was consulted.

Inclusion criteria. Inclusion criteria for the study were: i) Research population was colorectal cancer patients who were $\geq 65$. ii) The intervention of the experimental and control groups was laparoscopy and open surgery, respectively. iii) The endpoints included a 3- or 5-year survival rate. iv) The study design was RCT or other comparative study.

Exclusion criteria. Exclusion criteria for the study were: i) Non-elderly colorectal cancer patients. ii) Any study without a control group. iii) The patients were limited to tumor stage I or II. iv) No long-term outcomes were described. v) Non-English articles were excluded.

Data extraction. Data extraction was crosschecked synchronously between two authors to rule out any discrepancy. The third author made a final decision for the discrepancy. The following data were independently extracted for each included study: first author's surname, publication year, age of patients, tumor location, 3- and 5-year survival rate. If no 3- and 5-year survival rates were given, it was read from the results of the Kaplan-Meier curve using Engauge Digitizer version 4.1 (http://sourceforge.net/). If data sets overlapped or were duplicated, only the most recent data were included. If it was necessary, the authors were contacted for additional information.

Evaluation of methodological quality. The methodological quality of the included cohort studies was evaluated according to the Newcastle-Ottawa Scale (NOS). The concrete content was as follows: selection of patients, comparability, and evaluation of results. The cohort study was evaluated as low quality when the score was $\leq 5$ and excluded from our meta-analysis. By contrast, the study was evaluated as high quality when the score was $\geq 6$ and included in our meta-analysis.

Endpoint. The primary endpoint included the 3- and 5-year survival rates.

Statistical analysis. Statistical analysis was carried out using Stata12.0 software (Chicago, IL, USA). Risk ratio (RR) was calculated to express the effect size of categorical variables such as the 3- and 5-year survival rate. $\mathrm{I}^{2}$ statistic was used to show the heterogeneity between studies. The random effects model was used when there was obvious heterogeneity between studies $\left(I^{2} \geq 50 \%\right)$. The fixed effect model was used when there was no obvious heterogeneity between studies $\left(\mathrm{I}^{2}<50 \%\right)$.

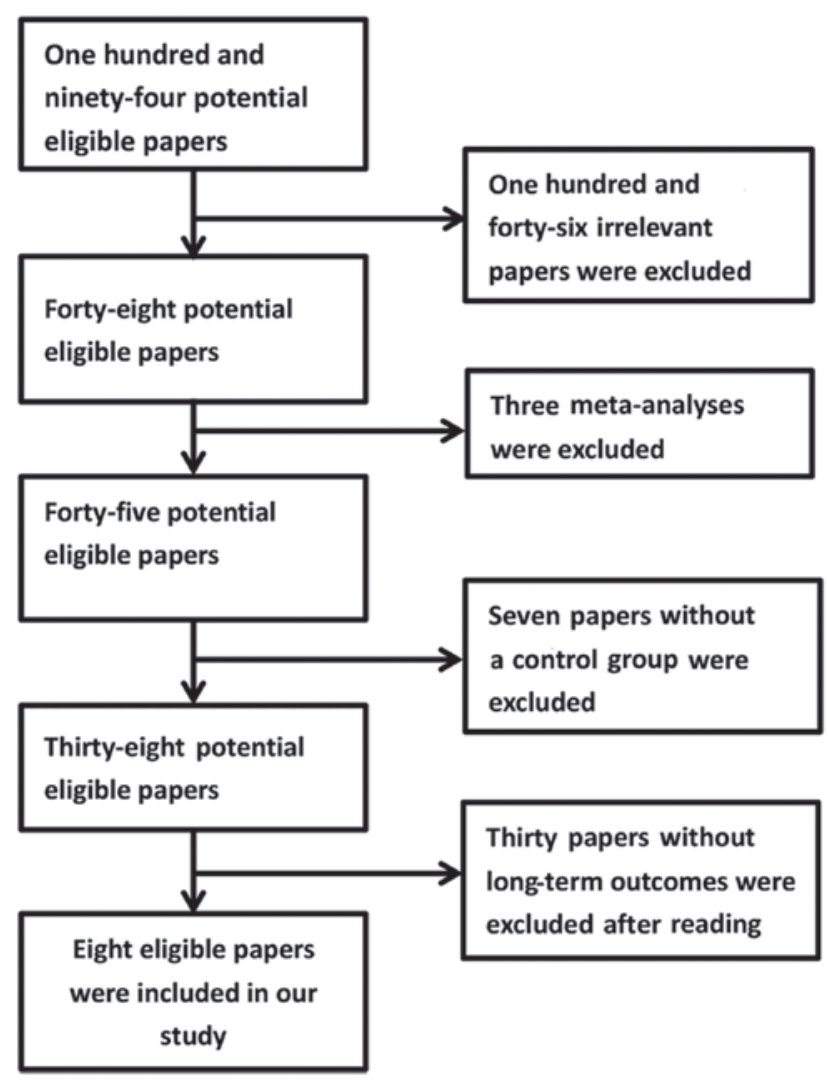

Figure 1. Flowchart of procedure selection.

The study was approved by Ethics Committee of Beijing Tiantan Hospital (Beijing, China). Publication consent is not applicable, since our paper does not contain any individual persons data. All data supporting the results are available.

\section{Results}

Eight cohort studies (9-16) were included in our meta-analysis. The selection procedure is shown in the flowchart of Fig. 1. No missing studies were found by reviewing the reference list of included articles. In total, 29,663 patients were incorporated in the 8 studies, in which 1,410 patients were in the laparoscopic group and the remaining 28,253 patients were in the open surgery group. Two studies limited the patient age to $\geq 65(10,13)$. Other studies limited the patient age to $\geq 70(9,11,12,14-16)$. Basic characteristics and methodological quality of included studies are shown in Table I.

Three-year survival rate. Eight cohort studies reported the 3-year survival rate in our meta-analysis (Table II) (9-16). One study showed the 3-year survival rate directly (12). Other studies showed the survival curve, by which the 3 -year survival rate can be calculated $(9-11,13-16)$. The $\mathrm{I}^{2}$ value was $54.8 \%$; thus, the random effects model was used to pool the 8 studies. The result indicated that laparoscopic surgery had a higher 3-year survival rate than open surgery $(\mathrm{RR}=0.74,95 \%$ CI: 0.61-0.90, $\mathrm{P}=0.003$ ) (Fig. 2).

Five-year survival rate. Six cohort studies reported a 5 -year survival rate in our meta-analysis (Table II). Two 
Table I. Basic characteristics and methodological quality of included studies.

\begin{tabular}{|c|c|c|c|c|c|c|c|c|c|}
\hline \multirow[b]{2}{*}{ Authors } & \multirow[b]{2}{*}{ Year } & \multirow{2}{*}{$\begin{array}{c}\text { Age, } \\
\text { years }\end{array}$} & \multirow[b]{2}{*}{ Location } & \multirow{2}{*}{$\begin{array}{l}\text { Study } \\
\text { design }\end{array}$} & \multirow[b]{2}{*}{ Total } & \multicolumn{3}{|c|}{ Sample size } & \multirow[b]{2}{*}{ (Refs.) } \\
\hline & & & & & & Lap & Open & Score & \\
\hline Zeng et al & 2015 & $\geq 70$ & $\mathrm{R}$ & CS & 294 & 112 & 182 & 7 & (16) \\
\hline She et al & 2013 & $\geq 75$ & $\mathrm{C}$ & $\mathrm{CS}$ & 434 & 189 & 245 & 6 & (14) \\
\hline Altuntas et al & 2012 & $\geq 70$ & $\mathrm{R}$ & $\mathrm{CS}$ & 90 & 56 & 34 & 7 & (9) \\
\hline Robinson et al & 2011 & $\geq 65$ & $\mathrm{CRC}$ & $\mathrm{CS}$ & 242 & 47 & 195 & 6 & (13) \\
\hline Cummings et al & 2012 & $\geq 65$ & $\mathrm{C}$ & $\mathrm{CS}$ & 27,436 & 424 & 27,012 & 7 & (10) \\
\hline Hinoi et al & 2015 & $\geq 80$ & $\mathrm{CRC}$ & CS & 918 & 459 & 459 & 6 & (11) \\
\hline Moon et al & 2016 & $\geq 80$ & $\mathrm{CRC}$ & $\mathrm{CS}$ & 142 & 71 & 71 & 6 & (12) \\
\hline Shigeta et al & 2016 & $\geq 80$ & $\mathrm{CRC}$ & $\mathrm{CS}$ & 107 & 52 & 55 & 5 & $(15)$ \\
\hline
\end{tabular}

Location, tumor location; R, rectal cancer; C, colon cancer; CRC, colorectal cancer; CS, cohort study; Lap, laparoscopic surgery; Open, open surgery.

Table II. Long-term outcomes of 8 cohort studies.

\begin{tabular}{|c|c|c|c|c|c|c|c|c|c|}
\hline \multirow[b]{3}{*}{ Authors } & \multicolumn{4}{|c|}{ 3-year survival rate } & \multicolumn{4}{|c|}{ 5-year survival rate } & \multirow[b]{3}{*}{ (Refs.) } \\
\hline & \multicolumn{2}{|c|}{ LAP } & \multicolumn{2}{|c|}{ OPEN } & \multicolumn{2}{|c|}{ LAP } & \multicolumn{2}{|c|}{ OPEN } & \\
\hline & Dead & Alive & Dead & Alive & Dead & Alive & Dead & Alive & \\
\hline Zeng et al & 11 & 101 & 38 & 144 & NM & NM & NM & NM & (16) \\
\hline She et al & 60 & 129 & 93 & 152 & 81 & 108 & 127 & 118 & (14) \\
\hline Altuntas et al & 13 & 43 & 20 & 14 & 24 & 32 & 25 & 9 & (9) \\
\hline Robinson et al & 13 & 34 & 57 & 138 & 23 & 24 & 76 & 119 & (13) \\
\hline Cummings et al & 155 & 269 & 10,751 & 16,261 & 212 & 212 & 13,803 & 13,209 & (10) \\
\hline Hinoi et al & 70 & 389 & 93 & 366 & 123 & 336 & 105 & 354 & (11) \\
\hline Moon et al & 14 & 57 & 18 & 53 & 21 & 50 & 26 & 45 & (12) \\
\hline Shigeta et al & 5 & 47 & 13 & 42 & NM & NM & NM & NM & (15) \\
\hline
\end{tabular}

LAP, laparoscopic surgery; OPEN, open surgery.

studies showed the 5-year survival rate directly $(10,14)$. Other studies showed the survival curve, by which the 5-year survival rate can be calculated $(9,11-13)$. The $\mathrm{I}^{2}$ value was $67.5 \%$; thus, the random effects model was used to pool the 6 studies. No statistical difference was found between laparoscopic surgery and open surgery with regard to the 5-year survival rate for the elderly colorectal cancer patients ( $\mathrm{RR}=0.93,95 \% \mathrm{CI}$ : 0.78-1.11, $\mathrm{P}=0.424$ ) (Fig. 3).

Publication bias. Funnel plot and Begg's test was used to evaluate the publication bias of the included studies. The shape of the funnel plot for the meta-analysis of studies on 3-year survival rate demonstrated symmetry $(\operatorname{Pr}>|z|=0.108)$ (Fig. 4).

\section{Discussion}

Colorectal cancer has become a disease of older age (2), which may be explained by the increased life expectancy of recent years (17). The decreasing functional reserve and comorbidities in elderly patients highlight the significance of operation style selection. In general, laparoscopic surgery can achieve decreased surgical trauma, faster postoperative recovery $(18,19)$ and equal long-term outcomes $(4,5,20)$ for colorectal cancer patients. Current studies comparing laparoscopy and open surgery in elderly colorectal cancer patients are limited and retrospective, making the short- and long-term outcomes unclear.

To the best of our knowledge, there are 3 meta-analyses comparing the short-term outcomes following laparoscopic and open colorectal resections in elderly populations. Grailey et al pooled 11 studies and concluded the reduction in length of hospital stay, intraoperative blood loss, incidence of postoperative pneumonia, time to return of normal bowel function, incidence of postoperative cardiac complications, and wound infections in the elderly population $(\geq 70)$ receiving laparoscopic colorectal resection (6). Li et al pooled 10 studies and concluded that laparoscopy can reduce the length of hospital stay, intraoperative blood loss, time to return of normal bowel 


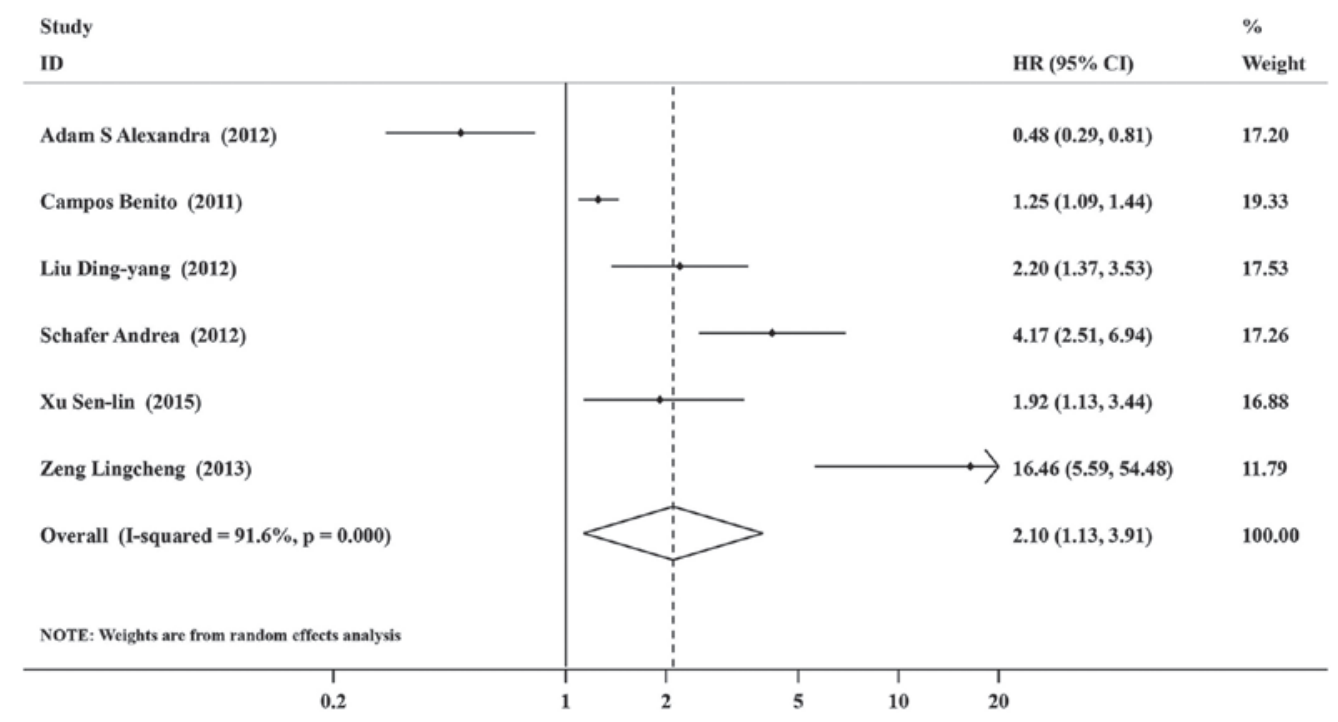

Figure 2. Meta-analysis of 3-year survival rate. RR, risk ratio; CI, confidence interval.

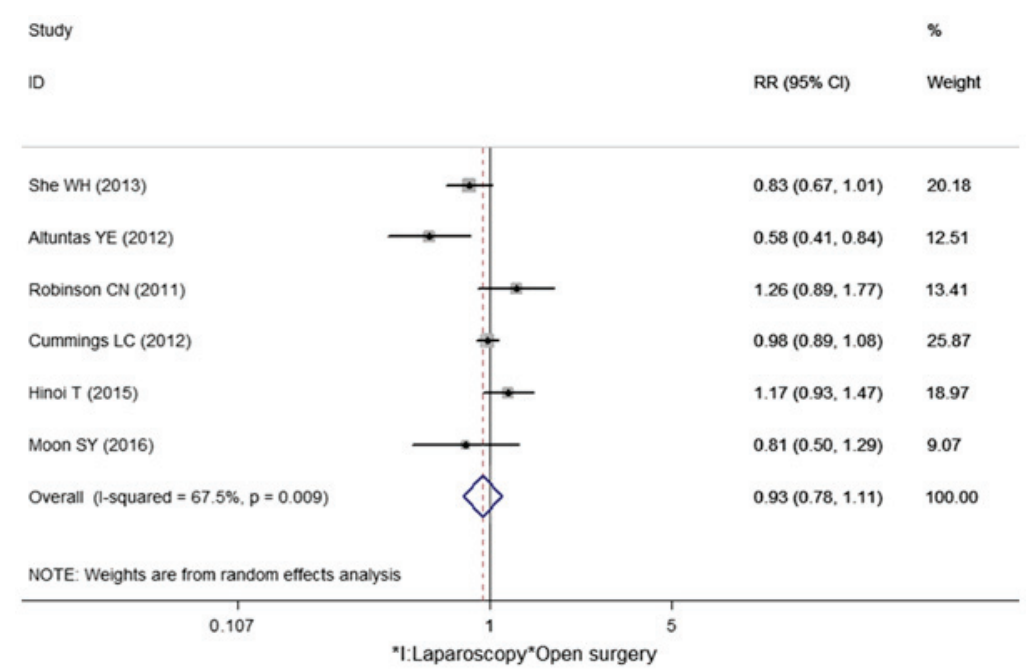

Figure 3. Meta-analysis of 5-year survival rate. RR, risk ratio; CI, confidence interval.

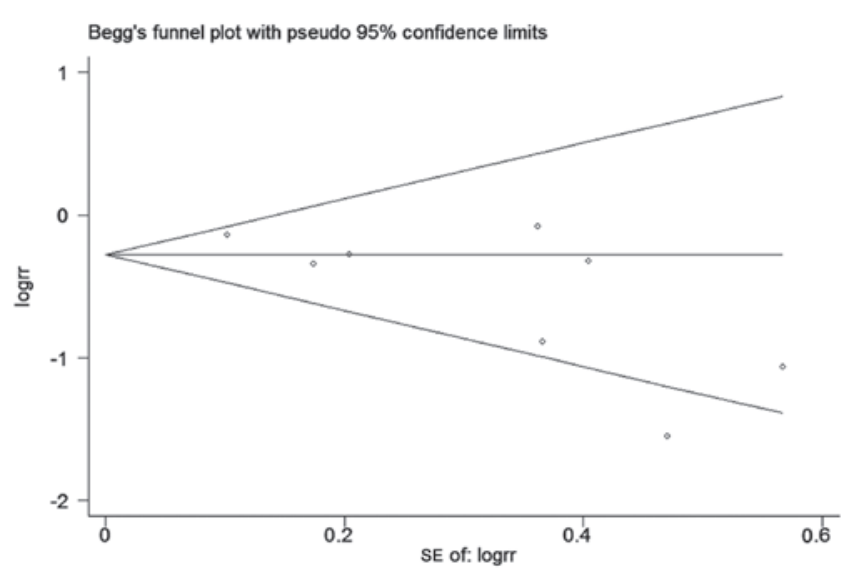

Figure 4. Funnel graph of included studies. SE, standard error; logrr, log risk ratio.

function, incidence of postoperative pneumonia, wound infection and postoperative ileus in the elderly population $(\geq 80)$ receiving laparoscopic colorectal resection (7). Xie et al performed a similar meta-analysis including 7 studies in octogenarian patients and concluded that the laparoscopic approach was associated with a lower rate of mortality, and prolonged ileus, quicker bowel function return, and shorter length of hospital stay (8). It is noteworthy that Xie et al found a lower rate of mortality in the laparoscopic group $(\mathrm{P}=0.03)(8)$, which is different from that identified by Grailey $(\mathrm{P}=0.82)(6)$ and Li et al $(\mathrm{P}=0.05)$ (7) in their respective meta-analyses. Thus, laparoscopic colorectal resection is associated with improved short-term outcomes, and the evidence was reinforced by several recent cohort studies $(12,15,21)$. However, the abovementioned meta-analyses did not report long-term outcomes.

We collected the previous comparative studies and performed a meta-analysis in long-term outcomes for elderly colorectal cancer patients. Our meta-analysis showed that, compared with open surgery, the laparoscopic surgery had a higher 3-year survival rate and an equivalent 5-year survival in elderly colorectal cancer patients. Koh et al performed a matched case-control study in octogenarian patients, and concluded that 
patients who have undergone laparoscopic surgery were associated with a better 1-year survival rate $(94.4$ vs. $75.0 \%, \mathrm{P}=0.09)$ compared with those who underwent open surgery (22). Of note is that the deaths in the open group were due to causes unrelated to surgery, the author explained the longer lasting effect of open surgery on physiological reserve may play an important role (22). In general population, no statistical significance was found in long-term outcomes between laparoscopic and open surgery $(4,5,20,23)$. Jiang et al pooled 12 studies and found disease-free survival $(\mathrm{OR}=1.80, \mathrm{P}=0.18)$ and overall survival $(\mathrm{OR}=1.44, \mathrm{P}=0.33)$ were similar between laparoscopic and open surgery for low rectal cancer (24). Feinberg et al performed a similar meta-analysis for pT4 colon cancer patients and concluded there was no significant difference in overall survival (HR, 1.28; 95\% CI, 0.94-1.72), and disease-free survival (HR, 1.20; 95\% CI, 0.90-1.61) between laparoscopic and open surgery (25). Thus, the issue raised is why long-term outcomes are different between the general and elderly populations. One reason may be that the poorer function reserve and more serious comorbidities after larger trauma of open surgery may impair the anti-tumor ability of immunologic function, which may cause earlier tumor recurrence and cancer-related death. By contrast, elderly colorectal cancer patients with advanced disease $(11,26,27)$, larger tumor size $(15,27,28)$ and emergency events (10) are often advised to undergo open surgery, which may lead to the open surgery group having inferior outcomes.

There are limitations to our meta-analysis that should be considered. First, all our eligible studies are non-RCTs, which may have selection bias. Second, obvious heterogeneity has been found between studies on the 3- and 5-year survival, which may be explained by confounding factors such as tumor location, adjuvant chemotherapy, level of hospital stay and surgeon. Third, only 8 studies were included in our meta-analysis; thus a larger cohort is required to confirm the results. Fourth, the age was limited to individuals aged $\geq 65$ in 2 studies $(10,13), \geq 70$ in 2 studies $(9,16), \geq 75$ in 1 study (14), and $\geq 80$ in 3 studies $(11,12,15)$. Varying age may play an important role on reliability. Fourth, the majority of the eligible studies did not show a 3-and 5-year survival rate directly, and this had to be estimated by survival curve, which may lead to errors. Finally, the difference of tumor location between eligible studies may also influence the reliability [colorectal cancer in 4 studies (11-13,15), colon cancer in 2 studies $(10,14)$, and rectal cancer in 2 studies $(9,16)]$. However, we performed funnel plot and Begg's test to evaluate the publication bias of the included studies and no obvious publication bias was found, which demonstrated our meta-analysis was reliable.

Improved long-term outcomes have been found for the laparoscopic surgery group for elderly colorectal cancer patients in our meta-analysis. However, most of the previous studies are non-RCTs exhibiting selection bias. Consequently, large sample and multicenter RCTs are needed to identify the optimal operation style for elderly colorectal cancer patients.

\section{Acknowledgements}

We would like to thank M. Yan and W.M. Yan for their assistance on our meta-analysis.

\section{References}

1. Ferlay J, Soerjomataram I, Dikshit R, Eser S, Mathers C, Rebelo M, Parkin DM, Forman D and Bray F: Cancer incidence and mortality worldwide: Sources, methods and major patterns in GLOBOCAN 2012. Int J Cancer 136: E359-E386, 2015.

2. Braendegaard Winther S, Baatrup G, Pfeiffer P and Qvortrup C; Academy of Geriatric Cancer Research (AgeCare): Trends in colorectal cancer in the elderly in Denmark, 1980-2012. Acta Oncol 55 (Suppl 1): S29-S39, 2016.

3. Hermans E, van Schaik PM, Prins HA, Ernst MF, Dautzenberg PJ and Bosscha K: Outcome of colonic surgery in elderly patients with colon cancer. J Oncol 2010: 865908, 2010.

4. Bayar R, Mzoughi Z, Djebbi A, Halek G and Khalfallah MT: Laparoscopic colectomy versus colectomy performed via laparotomy in the treatment of non-metastatic colic adenocarcinomas. Pan Afr Med J 25: 165, 2016 (In French).

5. Bonjer HJ, Deijen CL, Abis GA, Cuesta MA, van der Pas MH, de Lange-de Klerk ES, Lacy AM, Bemelman WA, Andersson J, Angenete $\mathrm{E}$, et al: A randomized trial of laparoscopic versus open surgery for rectal cancer. N Engl J Med 372: 1324-1332, 2015.

6. Grailey K, Markar SR, Karthikesalingam A, Aboud R, Ziprin P and Faiz O: Laparoscopic versus open colorectal resection in the elderly population. Surg Endosc 27: 19-30, 2013.

7. Li Y, Wang S, Gao S, Yang C, Yang W and Guo S: Laparoscopic colorectal resection versus open colorectal resection in octogenarians: A systematic review and meta-analysis of safety and efficacy. Tech Coloproctol 20: 153-162, 2016.

8. Xie M, Qin H, Luo Q, He X, Lan P and Lian L: laparoscopic colorectal resection in octogenarian patients: Is it Safe? A systematic review and meta-analysis. Medicine (Baltimore) 94: e1765, 2015.

9. Altuntas YE, Gezen C, Vural S, Okkabaz N, Kement M and Oncel M: Laparoscopy for sigmoid colon and rectal cancers in septuagenarians: A retrospective, comparative study. Tech Coloproctol 16: 213-219, 2012.

10. Cummings LC, Delaney CP and Cooper GS: Laparoscopic versus open colectomy for colon cancer in an older population: A cohort study. World J Surg Oncol 10: 31, 2012.

11. Hinoi T, Kawaguchi Y, Hattori M, Okajima M, Ohdan H, Yamamoto S, Hasegawa H,Horie H, Murata K, Yamaguchi S, et al: Laparoscopic versus open surgery for colorectal cancer in elderly patients: A multicenter matched case-control study. Ann Surg Oncol 22: 2040-2050, 2015

12. Moon SY, Kim S, Lee SY, Han EC, Kang SB, Jeong SY, Park KJ and Oh JH; SEoul COlorectal Group (SECOG): Laparoscopic surgery for patients with colorectal cancer produces better short-term outcomes with similar survival outcomes in elderly patients compared to open surgery. Cancer Med 5: 1047-1054, 2016.

13. Robinson CN, Balentine CJ, Marshall CL, Wilks JA, Anaya D, Artinyan A, Berger DH and Albo D: Minimally invasive surgery improves short-term outcomes in elderly colorectal cancer patients. J Surg Res 166: 182-188, 2011.

14. She WH, Poon JT, Fan JK, Lo OS and Law WL: Outcome of laparoscopic colectomy for cancer in elderly patients. Surg Endosc 27: 308-312, 2013.

15. Shigeta K, Baba H, Yamafuji K, Asami A, Takeshima K, Nagasaki K, Okamoto N, Murata T, Arai S, Kubochi K and Kitagawa Y: Effects of laparoscopic surgery on the patterns of death in elderly colorectal cancer patients: Competing risk analysis compared with open surgery. Surg Today 46: 422-429, 2016.

16. Zeng WG, Zhou ZX, Hou HR, Liang JW, Zhou HT, Wang Z, Zhang XM and Hu JJ: Outcome of laparoscopic versus open resection for rectal cancer in elderly patients. J Surg Res 193: 613-618, 2015.

17. Christensen K, Doblhammer G, Rau R and Vaupel JW: Ageing populations: The challenges ahead. Lancet 374: 1196-1208, 2009.

18. van der Pas MH, Haglind E, Cuesta MA, Fürst A, Lacy AM, Hop WC and Bonjer HJ; COlorectal cancer Laparoscopic or Open Resection II (COLOR II) Study Group: Laparoscopic versus open surgery for rectal cancer (COLOR II): Short-term outcomes of a randomised, phase 3 trial. Lancet Oncol 14: 210-218, 2013.

19. Yamamoto S, Inomata M, Katayama H, Mizusawa J, Etoh T, Konishi F, Sugihara K, Watanabe M, Moriya Y and Kitano S; Japan Clinical Oncology Group Colorectal Cancer Study Group: Short-term surgical outcomes from a randomized controlled trial to evaluate laparoscopic and open D3 dissection for stage II/III colon cancer: Japan Clinical Oncology Group Study JCOG 0404. Ann Surg 260: 23-30, 2014. 
20. Jeong SY, Park JW, Nam BH, Kim S, Kang SB, Lim SB, Choi HS Kim DW, Chang HJ, Kim DY, et al: Open versus laparoscopic surgery for mid-rectal or low-rectal cancer after neoadjuvant chemoradiotherapy (COREAN trial): Survival outcomes of an open-label, non-inferiority, randomised controlled trial. Lancet Oncol 15: 767-774, 2014.

21. Niitsu H, Hinoi T, Kawaguchi Y, Ohdan H, Hasegawa H, Suzuka I, Fukunaga Y, Yamaguchi T, Endo S, Tagami S, et al: Laparoscopic surgery for colorectal cancer is safe and has survival outcomes similar to those of open surgery in elderly patients with a poor performance status: Subanalysis of a large multicenter case-control study in Japan. J Gastroenterol 51: 43-54, 2016.

22. Koh FH, Wong J, Tan JK, Tan KK, Cheong WK and Lieske B: Laparoscopic colorectal surgery is safe and benefits octogenarian patients with malignant disease: A matched case-control study comparing laparoscopic and open colorectal surgery. Int J Colorectal Dis 30: 963-968, 2015.

23. Kim DH, Kim IY, Kim BR and Kim YW: Factors affecting the selection of minimally invasive surgery for stage 0/I colorectal cancer. Int J Surg 16: 44-48, 2015.
24. Jiang JB, Jiang K, Wang JJ, Dai Y, Xie FB and Li XM: Short-term and long-term outcomes regarding laparoscopic versus open surgery for low rectal cancer: A systematic review and meta-analysis. Surg Laparose Endosc Percutan Tech 25: 286-296, 2015.

25. Feinberg AE, Chesney TR, Acuna SA, Sammour T and Quereshy FA: Oncologic outcomes following laparoscopic versus open resection of pT4 colon cancer: A systematic review and meta-analysis. Dis Colon Rectum 60: 116-125, 2017.

26. Miyasaka Y, Mochidome N, Kobayashi K, Ryu S, Akashi Y and Miyoshi A: Efficacy of laparoscopic resection in elderly patients with colorectal cancer. Surg Today 44: 1834-1840, 2014

27. Nakamura T, Sato T, Miura H, Ikeda A, Tsutsui A, Naito M, Ogura N and Watanabe M: Feasibility and outcomes of surgical therapy in very elderly patients with colorectal cancer. Surg Laparosc Endosc Percutan Tech 24: 85-88, 2014.

28. Tominaga T, Takeshita H, Arai J, Takagi K, Kunizaki M, To K, Abo T, Hidaka S, Nanashima A, Nagayasu T and Sawai T: Short-term outcomes of laparoscopic surgery for colorectal cancer in oldest-old patients. Dig Surg 32: 32-38, 2015. 